\title{
Ischemic Monomelic Neuropathy: The Case for Reintroducing a Little-Known Term
}

\author{
Paul Winston (1D, Dannika Bakker
}

\begin{abstract}
Ischemic monomelic neuropathy (IMN) is a little-known, painful axonal neuropathy, secondary to vascular occlusion or steal phenomenon. It typically occurs after vascular bypass, hemodialysis fistulization, or diabetic microvascular disease in the absence of significant clinical features of ischemia. There is limited literature to assist in the characterization and diagnosis of this condition. We describe three patients with IMN with no surgical or peripheral vascular disease history who exhibited spontaneous, persistent foot pain, edema numbness, and weakness with denervation on needle electromyogram in a distal lower leg peripheral nerve distribution. Occlusive disease was found in all patients on angiogram, requiring vascular bypass surgery.
\end{abstract}

RÉSUMÉ : Un argument en faveur d'un réexamen de la neuropathie ischémique monomélique, complication qui demeure encore peu connue. La neuropathie ischémique monomélique (NIM) est une complication axonale douloureuse dont on sait peu de choses sinon qu'elle est consécutive à une occlusion vasculaire ou au phénomène du vol coronarien (steal phenomenon). En l'absence de caractéristiques cliniques de nature ischémique notables, la NIM a aussi souvent tendance à se manifester après un pontage vasculaire, une fistulisation par hémodialyse ou des complications micro-vasculaires d'origine diabétique. Il n'existe à ce sujet qu'une littérature scientifique limitée pour nous aider à caractériser et à diagnostiquer une telle complication. Nous voulons donc décrire ici les cas de trois patients atteints de NIM. Mentionnons que ces derniers n'avaient pas d'antécédents de maladie vasculaire périphérique ou d'interventions chirurgicales. Mentionnons aussi qu'ils ont donné à voir des douleurs spontanées aux pieds ayant persisté mais aussi un engourdissement lié à la présence d'un oedème. À cela il faut ajouter de la faiblesse jumelée à une dénervation qui a affecté la distribution périphérique des nerfs de la partie inférieure distale de la jambe. Un tel phénomène a été observé lors d'un examen d'électromyographie (EMG) par aiguille. Enfin, soulignons que des complications occlusives ont été détectées chez tous les patients nécessitant un pontage vasculaire (vascular bypass surgery) à la suite d'une procédure d'angiographie.

Keywords: Acquired and hereditary neuropathies, Vascular neurology, Electrodiagnosis, Pain

doi:10.1017/cjn.2020.88

Can J Neurol Sci. 2020; 47: 697-699

Ischemic monomelic neuropathy (IMN) is a little-known consequence of vascular compromise characterized as a noncompressive occlusion of blood supply or steal phenomenon causing axonal mononeuropathies in the distal limb, without compromising the muscles and other tissues. ${ }^{1}$ Most published case studies have identified IMN secondary to vascular access surgery or in patients with known peripheral arterial disease (PAD) or diabetic microvascular disease. ${ }^{2-4}$ IMN may occur in the absence of clinical features of ischemia, such as activityinduced pain or ulcerations. ${ }^{2}$ Reports of IMN presenting as nerve infarction from unrecognized vascular occlusion in the absence of surgical intervention or known PAD remain sparse since a 1983 sentinel paper by Wilbourn. ${ }^{1}$

We were introduced to IMN after the unexpected finding of extensive vascular occlusions as the cause of a peroneal nerve infarction. A 42-year-old healthy female was referred for neurodiagnostic assessment for a suspected diagnosis of radiculopathy with superimposed complex regional pain syndrome type II (CRPS II) of the foot, despite an unremarkable computed tomography (CT) lumbar spine. She presented with back pain, with progressive onset of a grossly swollen, painful distal left leg with numbness, and toe and ankle extensor weakness. Nerve conductions were unobtainable due to pain and edema. Electromyogram (EMG) revealed increased insertional activity with florid denervation of the tibialis anterior and extensor digitorum brevis (EDB) with polyphasic large motor unit action potentials with reduced recruitment. Prednisone was given for CRPS II, and the pain and swelling abated. ${ }^{5}$ At 2 weeks, pain reemerged, and a CT scan was ordered to assess for retroperitoneal pathology. The scan and subsequent CT angiogram (CTA) found a filling defect from the distal thoracic to proximal abdominal aorta, renal artery stenosis, renal infarction, and extensive occlusion of the bilateral leg arteries including near-complete occlusion of the left lower extremity arterial supply. Notable clinical features included the presence of pedal pulses on presentation to the vascular surgeon, and the lower leg pain was temporarily abated by a peroneal

From the Division of Physical Medicine and Rehabilitation, University of British Columbia, Victoria, British Columbia, Canada (PW); and Department of Family Medicine, Dalhousie University, Halifax, Nova Scotia, Canada (DB)

Received March 31, 2020. Final Revisions Submitted April 24, 2020. Date of ACCEPTANCE APRIL 24, 2020.

Correspondence to: Paul Winston, Victoria General Hospital, 1 Hospital Way, Victoria, BC V8Z 6R5, Canada. Email: paul.winston@viha.ca 


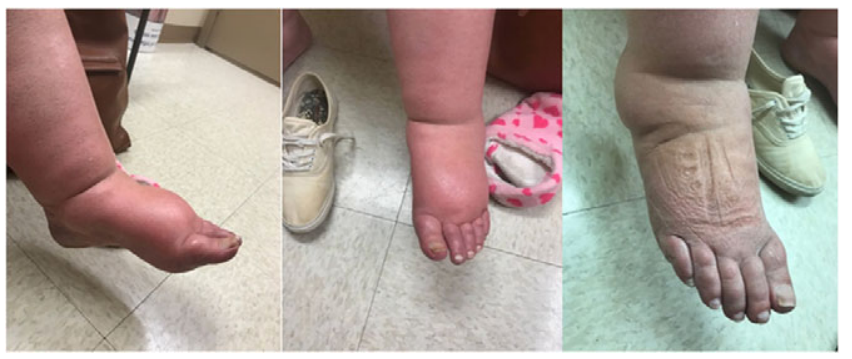

Figure 1: Two views of the affected left foot in a 68-year-old female and the unaffected side.

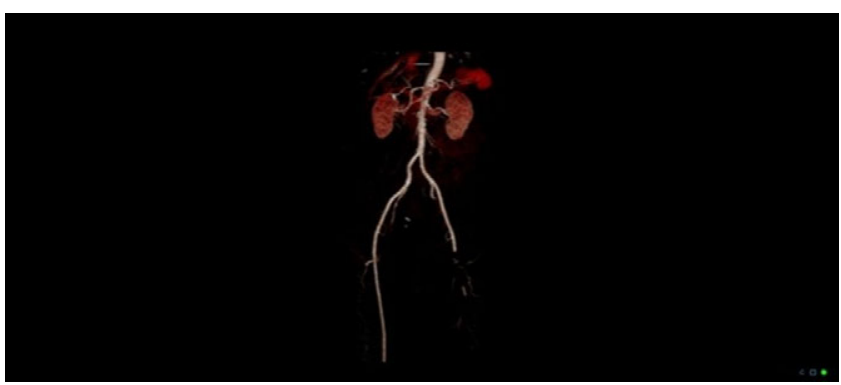

Figure 2: The computed tomography angiogram (CTA) of a 68-year-old patient with ischemic monomelic neuropathy (IMN) of the left leg.

nerve block at the fibular head. Limb salvage surgery was ultimately nonviable, resulting in an above-knee amputation.

With familiarity that IMN can present as nerve pain without overt signs of vascular ischemia, we present two cases where IMN was recognized at presentation.

A 68-year-old female was referred for assessment of possible CRPS with a 3-month history of an atraumatic, painful, swollen left foot. The foot was grossly edematous (Figure 1). Sensation was patchy. There was weakness in the toe and hallucis extension. The foot was too swollen to palpate pulses. A Doppler ultrasound, obtained during an emergency department visit, had an incidental finding of left-sided popliteal occlusion with good collateral blood flow. Nerve conduction studies were not possible due to edema. The EMG revealed florid denervation to the EDB only. As the diagnosis of IMN was suspected, an urgent CTA was ordered and the patient was instructed to go to hospital if the pain worsened. Unfortunately, the CTA was not expedited. The family physician called about increasing pain. Prednisone was suggested, which reduced the pain intensity and swelling. Two weeks after the EMG, she developed severe left foot pain and went to hospital, where a CTA revealed embolic occlusions of the left superficial, profunda, and common femoral arteries (Figure 2). The limb was successfully salvaged via embolectomy and angioplasty.

A 52-year-old diabetic male presented to an internist with a swollen right knee, progressing to a diffusely swollen lower limb. He was a smoker with a history of gout. The C-reactive protein was $22 \mathrm{mg} / \mathrm{L}$. No deep vein thrombosis was found on Doppler ultrasound. He was treated with colchicine for presumptive gout. One month later, the knee swelling resolved, but he described numbness and tingling in the lower leg and severe lower leg pain. The internist started $40 \mathrm{mg}$ of prednisone daily, with improvement in pain and swelling. He was referred for electrodiagnosis. Upon assessment, the leg was not swollen, but the right foot had a slightly darker hue. There was mild weakness in the toe extensors and decreased pinprick sensation in the right peroneal nerve distribution. With IMN in mind, palpation of pulses was performed. Neither the right dorsalis pedis pulse nor the posterior tibial was palpable, though robust on the left. A portable ultrasound with a Doppler feature found no flow at the right dorsalis pedis and minimal flow in the posterior tibial. The nerve conduction studies revealed normal tibial motor and sural sensory responses. The peroneal motor to EDB amplitude was $1.2 \mathrm{mV}$ at the ankle, with no conduction block. The left side was normal. The EMG revealed a normal tibialis anterior and gastrocnemius. The EDB and peroneus longus showed large polyphasic motor units with a decreased recruitment pattern. An urgent CTA with abdominal aorta and femoral runoff revealed on the right a small popliteal artery aneurysm with mural thrombus and an occlusion of the dorsalis pedis at the ankle. The posterior tibial artery was patent. The left leg revealed a $3-\mathrm{cm}$ aneurysm to the proximal popliteal artery with a thrombosed lumen and mural thrombus and normal runoff. Urgent vascular surgery consult was obtained, but surgery was delayed due to the COVID-19 pandemic.

To investigate IMN in patients without a known history of PAD, a systematic search by the College of Physicians and Surgeons of British Columbia librarians was conducted of English-language studies published between 1980 and 2020 using electronic databases MEDLINE, EMBASE, CINAHL, Cochrane Database of Systematic Reviews, and Cochrane Central Register of Controlled Trials. The term IMN revealed limited citations. The search was expanded to combine ischemia and neuropathy, with extremities, occlusion, diabetes, or fistulae. Reference lists of systematic reviews and included articles were scanned to expand the data set. Of the 230 citations, 34 had detailed descriptions of IMN. The great majority were in the vascular literature and concerned post bypass procedures.

Few papers in the neurologic literature address or describe IMN. A 1996 paper studied IMN in known chronically ischemic legs. ${ }^{6}$ A review article included ischemic neuropathy in acute occlusive disease. ${ }^{7}$ A 1989 case reported on IMN occurring after bypass surgery. ${ }^{8}$ Similarly, a 1993 paper described IMN in the arm after hemodialysis shunting or occlusion in the upper extremity. ${ }^{9}$ A 2001 paper described chronic IMN after screening 19 patients with known chronic vascular disease for signs of peripheral disease. ${ }^{2}$

The literature suggests the typical feature of IMN as a pattern of unilateral diffuse painful mononeuropathies. ${ }^{1,2}$ It is notable that larger nerves have a dedicated capillary system, the vasa nervorum, to manage their metabolic needs. Restriction of the larger vessels supplying either or both can lead to microvascular changes that decrease peripheral blood supply and lead to axonal death. ${ }^{7}$ Further disruption may occur if the reduced flow damages the Schwann cells, disrupting the myelin sheath. Generally, muscle and other tissues are unaffected. ${ }^{1}$ Their escape is attributed to the higher oxygen demands of nerves. ${ }^{2}$

IMN is predominantly described in diabetics due to vulnerability to ischemia. ${ }^{2,4}$ Hemodialysis fistula creations are associated with a higher incidence of IMN, especially for sites with minimal collateral supply. In these patients, surgeries may be needed to revert the fistula despite no reasonable cause for ischemia on visual, tactile, or even ultrasonic exploration. ${ }^{4}$ Wilbourn described 14 cases of IMN occurring most commonly after bypass or hemodialysis fistula surgery, and 6 were due to 
thromboembolic disease. ${ }^{1}$ Other factors linked to IMN include hypertension, age, alcohol use, and female sex. ${ }^{3}$

The affected limb is unlikely to present as ischemic and can still be warm, pink, and have palpable pulses. ${ }^{1}$ Chronic IMN patients may show signs of decreased perfusion, hair loss, nonhealing ulcers, and other trophic skin changes, due to the systemic conditions permitting IMN. ${ }^{2}$ Classically, IMN presents as unilateral pain, paresthesia, and numbness, with or without motor weakness, in the absence of other ischemic symptoms. ${ }^{1}$ At an electrodiagnostic level, the findings include predominantly decreased amplitudes and secondary reduction in conduction velocities in both sensory and motor nerves, consistent with axonal loss. ${ }^{4}$

As noted by Wilbourn, patients with IMN are commonly misdiagnosed with conditions such as lumbar radiculopathy. Our patients presented without typical features of vascular ischemia or PAD; their pain was compatible with nerve ischemia or infarction, as noted by the response to oral prednisone having an effect on CRPS II symptoms as well as the lidocaine nerve block.

A literature review to investigate our initial patient was ineffective until the term IMN was proposed by a national expert. Knowledge of IMN led to an enhanced clinical pattern recognition and heightened suspicion for the two described cases, leading to rapid interventions. These presentations could inform clinical judgment on investigating sudden-onset atypical lower limb pain as potential IMN. Our cases identify the limited literature nearly four decades after Wilbourn's seminal paper to assist in diagnosing IMN in patients with no known history of PAD.

\section{ACKNOWLedGements}

Thanks are due to Dr Kristine Chapman for listening to the case description and for suggesting the term ischemic monomelic neuropathy.

\section{Disclosures}

The authors have no conflicts of interest to declare.

\section{Statement of Authorship}

PW is the clinician that conceived the original idea and provided all care. DB assisted in the literature review and manuscript preparation.

\section{REFERENCES}

1. Wilbourn AJ, Furlan AJ, Rulley W, Ruschhaupt W. Ischemic monomelic neuropathy. Neurology. 1983;33(4):447-51.

2. Weinberg DH, Simovic D, Isner J, Ropper AH. Chronic ischemic monomelic neuropathy from critical limb ischemia. Neurology. 2001;57(6):1008-12.

3. Shin KJ, Park JK. Neurological and electrophysiological parameters as outcome measurements for peripheral arterial occlusive disease. Ann Vasc Surg. 2014;28(7):1703-11. doi: 10.1016/j. avsg.2014.04.004

4. Sheetal S, Byju P, Manoj P. Ischemic monomelic neuropathy. J Postgrad Med. 2017;63(1):42-3. doi: 10.4103/0022-3859. 194221

5. Jamroz A, Berger M, Winston P. Prednisone for acute complex regional pain syndrome: a retrospective cohort study. Pain Res Manag. 2020;2020:1-10. doi: 10.1155/2020/8182569

6. Nukada H, Van Rij AM, Packer SGK, McMorran PD. Pathology of acute and chronic ischaemic neuropathy in atherosclerotic peripheral vascular disease. Brain. 1996;119(Pt 5):1149-60. doi: 10.1093/brain/119.5.1449

7. Ugalde V, Rosen BS. Ischemic peripheral neuropathy. Phys Med Rehabil Clin N Am. 2001;12(2):365-80. Available at: http://www. ncbi.nlm.nih.gov/pubmed/11345013; accessed January 4, 2019.

8. Levin KH. AAEE case report \#19: ischemic monomelic neuropathy. Muscle Nerve. 1989;12(10):791-95. doi: 10.1002/mus.88012 1002

9. Kaku DA, Malamut RI, Frey DJ, Parry GJ. Conduction block as an early sign of reversible injury in ischemic monomelic neuropathy. Neurology. 1993;43(6):1126-30. doi: 10.1212/WNL.43.6. 1126 